This is a preprint version of the paper published in J Dermatol Sci. 2016 Oct;84(1):17-23. doi: 10.1016/j.jdermsci.2016.07.005.

(C) 2016 Elsevier. This manuscript version is made available under the CC-BY-NC-ND 4.0 license

TITLE PAGE

\title{
Decreased fibrinolytic potential and morphological changes of fibrin structure in dermatitis herpetiformis
}

Anna Göröga ${ }^{a}$, Krisztián Németha ${ }^{a}$ László Szabóc, Balázs Mayer ${ }^{\mathrm{a}}$, Pálma Sillóa, Krasimir Kolev ${ }^{\mathrm{b} 1}$, Sarolta Kárpátia1

a Department of Dermatology, Venereology and Dermatooncology, Semmelweis University, Budapest, Hungary

${ }^{\mathrm{b}}$ Department of Medical Biochemistry, Semmelweis University, Budapest, Hungary ${ }^{c}$ Institute of Materials and Environmental Chemistry, Research Centre for Natural Science, Hungarian Academy of Sciences, Budapest, Hungary

${ }^{1}$ These authors contributed equally to the study.

Address correspondence to:

Sarolta Kárpáti MD, PhD, DrSc

Department of Dermatology, Venereology and Dermatooncology,

Semmelweis University, Budapest, Hungary

Mária u 41, Budapest H-1085, Hungary

E-mail: skarpati@t-online.hu 
This is a preprint version of the paper published in J Dermatol Sci. 2016 Oct;84(1):17-23. doi: 10.1016/j.jdermsci.2016.07.005.

(C) 2016 Elsevier. This manuscript version is made available under the CC-BY-NC-ND 4.0 license

The authors have no conflict of interest to declare.

This work was supported by the Hungarian Scientific Research Fund [OTKA 112612 and OTKA NN 114460].

Text word count: 2876

Number of references: 31

Number of tables: 2

Number of figures: 3

Abbreviations: $A B$, antibody/antibodies; $D H$, dermatitis herpetiformis; ELISA, enzyme-linked immunosorbent assay; EMA, endomysial antibodies; GFD, glutenfree diet; Ig, immunoglobulin; SEM, Scanning Electron Microscopy; TG, transglutaminase, TG2, tissue transglutaminase; TG3, epidermal transglutaminase; tPA, tissue plasminogen activator 
This is a preprint version of the paper published in J Dermatol Sci. 2016 Oct;84(1):17-23. doi: 10.1016/j.jdermsci.2016.07.005.

(C) 2016 Elsevier. This manuscript version is made available under the CC-BY-NC-ND 4.0 license

\section{ABSTRACT}

Background: Recently, high prevalence of cryofibrinogenaemia has been observed in plasma of untreated dermatitis herpetiformis $(\mathrm{DH})$ patients, and the pathological $\lg \mathrm{A}$ and TG3 deposits in the papillary dermis were found to co-localize with fibrin and fibrinogen.

Objective: To study the fibrinolytic potential in plasma of untreated, dapsone and or/ gluten-free diet treated DH patients as well as the in vitro effect of dapsone on the fibrinolytic profile.

Method: Plasma samples of $23 \mathrm{DH}$ patients, 19 healthy subjects and 5 pemphigus vulgaris patients were investigated by a turbidimetric-clot lysis assay. Out of them 5 DH plasma samples representing different fibrinolytic parameters, and 3 healthy controls were selected for parallel fibrin clot preparation. The clot fibrin structure was examined by scanning electron microscopy (SEM), and the diameters of 900 fibrin fibres were determined in each clot.

Results: A significantly prolonged clot lysis time was detected in untreated $\mathrm{DH}$ patients. The turbidity values of $\mathrm{DH}$ plasma clots indicated an altered fibrin structure that was also confirmed by SEM: significantly thicker fibrin fibers were observed in untreated, TG3 antibody positive DH patients compared to healthy controls, whereas the fiber diameters of dapsone-treated patients were similar or thinner than the control values. In line with the structural changes of fibrin, the 
This is a preprint version of the paper published in J Dermatol Sci. 2016 Oct;84(1):17-23. doi: 10.1016/j.jdermsci.2016.07.005.

(C) 2016 Elsevier. This manuscript version is made available under the CC-BY-NC-ND 4.0 license

fibrinolytic profile of $5 \mathrm{DH}$ patients under dapsone treatment approached the control values.

Conclusion: This study revealed that the fibrinolytic potential was impaired in the plasma of untreated $\mathrm{DH}$ patients, whereas dapsone corrected the fibrinolytic defect. These data suggest a pathogenic role for plasma-derived factors in the development of skin symptoms and add a new aspect to the long-known beneficial, symptomatic effect of dapsone in active $\mathrm{DH}$.

Key words: dermatitis herpetiformis, fibrin, fibrinolysis, dapsone, transglutaminase 3 
This is a preprint version of the paper published in J Dermatol Sci. 2016 Oct;84(1):17-23. doi: 10.1016/j.jdermsci.2016.07.005.

(C) 2016 Elsevier. This manuscript version is made available under the CC-BY-NC-ND 4.0 license

\section{INTRODUCTION}

Dermatitis herpetiformis (DH) is a chronic blistering skin disease characterized by grouped pruritic papules, vesicles above the elbows, knees and buttocks, but acral purpuras are also common findings mostly on fingers or toes [[1], [2]]. Epidermal transglutaminase (TG3) is the major antigen of $\mathrm{DH}[3]$, and it forms insoluble aggregates with granular immunoglobulin A ( $\lg A)$ depositions in the papillary dermis. On the other hand, very early observations evidenced an extravascular fibrinogen and fibronectin staining along the papillary IgA in $\mathrm{DH}$ [[4], [5], [6], [7]]. A preserved activity of TG3 within the cutaneous IgA-fibrinogen complexes was also detected recently [8].

DH develops in a subpopulation of patients with underlying gluten sensitive enteropathy, in whom transglutaminase 2 (TG2) and TG3 antibodies (AB) are typically present. The recent observation that untreated $\mathrm{DH}$ patients have a high prevalence of cryofibrinogenemia in plasma [9] prompted us to examine $\mathrm{DH}$ plasma samples as a possible source of skin deposited fibrinogen along with IgA and TG3. It has been shown previously that dapsone, the symptomatic treatment in $\mathrm{DH}$, seems to decrease the amount of cryofibrinogen in vitro [10], but the exact mechanism of action is unknown. 
This is a preprint version of the paper published in J Dermatol Sci. 2016 Oct;84(1):17-23. doi: 10.1016/j.jdermsci.2016.07.005.

(C) 2016 Elsevier. This manuscript version is made available under the CC-BY-NC-ND 4.0 license

The presence of plasma cryofibrinogen is indicating a temperature dependent pathology associated with the function of circulating fibrinogen. The clearance of cryofibrinogen aggregates is mediated probably by the same proteolytic mechanism as the resolution of intravascular fibrin clots, which are formed when plasma fibrinogen is converted to fibrin by thrombin. Fibrin monomers polymerize through non-covalent interactions and by isopeptide bond formation between the monomers. This clot formation/stabilization is a common phenomenon also in inflammation [[11], [12]]. The major route for elimination of fibrin clots is their proteolytic degradation by plasmin formed from plasma plasminogen by tissue plasminogen activator (tPA) [13] and this route is very sensitive to a variety of biomechanical, chemical and cellular factors [14].

In this study we investigated the plasma and serum of $\mathrm{DH}$ patients for their capacity to form and resolve fibrin clots and observed a decreased fibrinolytic potential associated with a modified fibrin structure, as well as a reversal of the fibrinolytic abnormalities by dapsone, an effective symptomatic therapeutic agent in $\mathrm{DH}$.

\section{MATERIALS AND METHODS}

\section{Patients and controls}

The diagnosis of $\mathrm{DH}$ was based on clinical symptoms, routine skin histology and on presence of granular $\lg A$ precipitates in the papillary dermis by direct immunofluorescence. In all DH patients the IgA type TG3 enzyme-linked 
This is a preprint version of the paper published in J Dermatol Sci. 2016 Oct;84(1):17-23. doi: 10.1016/j.jdermsci.2016.07.005.

(C) 2016 Elsevier. This manuscript version is made available under the CC-BY-NC-ND 4.0 license

immunosorbent assay (ELISA) and in all DH patients and healthy subjects the IgA type TG2 ELISA and/or the endomysial AB (EMA) tests were also performed. None of the patients and healthy subjects had a selective IgA deficiency and none of them received therapy with known impact on the haemostatic system before or at evaluation.

Twenty-three $\mathrm{DH}$ patients, 17 males and 6 females, mean age $41 \pm 13$ years (range 21-74) and 12 healthy controls, 6 males and 6 females, mean age $33 \pm 10$ years (range 23-55) were enrolled in the turbidimetric clot-lysis assay study. Out of the total $23 \mathrm{DH}$ patients the following subgroups were also selectively evaluated: a, 7/23 untreated $\mathrm{DH}$ patients with skin symptoms (no gluten-free diet (GFD), no dapsone treatment) b, 5/23 under dapsone medication $\underline{(3 / 5 \text { also under intermittent }}$ GFD) c, 11/23 under continuous GFD (Table 1). Dapsone was given to patients who wanted to get rapid improvement or received the medication in other clinics.

As a separate study 5 female pemphigus vulgaris patients (see above, Table 1) and 7 healthy subjects, 2 males and 5 females, mean age $44 \pm 18$ years (range 2572 years) were examined by a turbidimetric clot-lysis assay.

All procedures have been approved by the Semmelweis University Regional and Institutional Committee of Science and Research Ethics (88/2013.) and were in accordance with the Helsinki Declaration. All subjects gave an informed written consent to participate in this study.

\section{Direct immunofluorescence studies}


This is a preprint version of the paper published in J Dermatol Sci. 2016 Oct;84(1):17-23. doi: 10.1016/j.jdermsci.2016.07.005.

(C) 2016 Elsevier. This manuscript version is made available under the CC-BY-NC-ND 4.0 license

The DIF was performed on $10 \mu \mathrm{m}$ frozen sections of the patients' skin using fluorescein isothiocyanate (FITC) conjugated, goat antihuman complement 3 (C3), IgA, IgG and IgM AB (Dako, Glostrup, Denmark).

\section{Serological markers}

EMA were measured by indirect immunofluorescence according to the manufacturer's instructions (ImmuGlo IMMCO Diagnostics, Buffalo, NY).

TG3 and TG2 IgA AB were tested in duplicate by commercial ELISA kits. The cutoff value for the TG3 IgA ELISA (Immundiagnostik, Bensheim, Germany) was 22 AU/ml, for TG2 IgA ELISA (Orgentec Diagnostika, Mainz, Germany) was 10 AU/ml according to the manufacturer's instruction.

\section{Turbidimetric clot-lysis assay and the in vitro effect of dapsone}

This assay was described earlier [15]. Briefly: freshly, simultaneously prepared plasma and serum samples were analysed within $1 \mathrm{~h}$ after collection without freezing to avoid cryoprecipitation. Plasma clots were prepared with $5 \mu \mathrm{L}$ thrombin (30 $\mathrm{U} / \mathrm{mL}$ ) added to a mixture of $50 \mu \mathrm{L}$ citrated human blood plasma (collected in $3.8 \%$ sodium citrate blood collection tube) and $50 \mu \mathrm{L} 0.1 \mu \mathrm{g} / \mathrm{ml}$ tPA (Actilyse, Boehringer Ingelheim, Germany) in 10 mM HEPES-NaOH pH 7.4 buffer containing $150 \mathrm{mM} \mathrm{NaCl}$ and $25 \mathrm{mM} \mathrm{CaCl}$. When serum clot lysis was examined, the HEPES buffer contained also $2 \mathrm{mg} / \mathrm{ml}$ fibrinogen (human, plasminogen-depleted, Calbiochem, LaJolla, CA). The course of clot formation and dissolution was 
This is a preprint version of the paper published in J Dermatol Sci. 2016 Oct;84(1):17-23. doi: 10.1016/j.jdermsci.2016.07.005.

(C) 2016 Elsevier. This manuscript version is made available under the CC-BY-NC-ND 4.0 license

monitored by measuring the light absorbance at $340 \mathrm{~nm}\left(\mathrm{~A}_{340}\right)$ at $37^{\circ} \mathrm{C}$ with a Zenyth 200rt microplate spectrophotometer (Anthos Labtec Instruments $\mathrm{GmbH}$, Salzburg, Austria). The lysis time, defined as the time needed to reduce the turbidity of the clot to half-maximal value, was used as a quantitative parameter of the fibrinolytic activity, whereas the maximal turbidity $\left(\mathrm{A}_{340 \mathrm{max}}\right)$ was an indicator of the fiber size of fibrin [16]. Higher turbidity indicates thicker fiber diameters and larger clot pores [[17], [18]].

Dapsone at $5 \mu \mathrm{g} / \mathrm{ml}$ [19] was applied directly to freshly prepared plasma samples of 2 untreated $\mathrm{DH}$ patients (2 males, 68 and 74 years old, see Patient 22 and 23 in Table 1) and 2 healthy subjects ( 2 males, 29 and 39 years old) for 30 min prior the clotting in the fibrinolytic assay.

\section{Scanning electron microscope (SEM) imaging of plasma clots}

Four out of 34 plasma samples were selected for SEM according to their lysiscurves ( $\mathrm{A}_{340 \max }$ values), Patient 1,2,3 (P1, P2, P3) (Table 1) and a healthy subject with average control turbidity. $P 1$, who showed the highest $A_{340 \max }$, was a TG2-TG3 AB positive, untreated $\mathrm{DH}$ patient, $\mathrm{P} 2$, who showed the lowest $\mathrm{A}_{340 \mathrm{max}}$, was a TG2TG3 $A B$ negative, dapsone and GFD treated $\mathrm{DH}$ patient and $\mathrm{P} 3$ with medium turbidity was a TG2 AB negative-TG3 $A B$ positive, only dapsone treated $\mathrm{DH}$ patient (Fig. 2A, Table 1). SEM evaluation of fibrin from further 2 untreated, seronegative $\mathrm{DH}$ patients (P22, P23 in Table 1) and 2 healthy subjects were done to 
This is a preprint version of the paper published in J Dermatol Sci. 2016 Oct;84(1):17-23. doi: 10.1016/j.jdermsci.2016.07.005.

(C) 2016 Elsevier. This manuscript version is made available under the CC-BY-NC-ND 4.0 license

characterize the fibrin structure before and after in vitro dapsone addition (see above).

Plasma clots were prepared as described above for the clot-lysis assay (omitting tPA from the reaction mixture). Following 30 -min clotting at $37^{\circ} \mathrm{C}$, clots were fixed in $1 \%(v / v)$ glutaraldehyde in $100 \mathrm{mM} \mathrm{Na-cacodylate} \mathrm{pH} 7.2$ buffer for $16 \mathrm{~h}$. The fixed samples were dehydrated in a series of ethanol dilutions $(20-96 \%(v / v)), 1: 1$ mixture of $96 \%(v / v)$ ethanol/acetone and pure acetone followed by critical point drying with $\mathrm{CO}_{2}$ in E3000 Critical Point Drying Apparatus (Quorum Technologies, Newhaven, UK). The specimens were mounted on adhesive carbon discs, sputter coated with gold in SC7620 Sputter Coater (Quorum Technologies, Newhaven, UK) and images were taken with SEM EVO40 (Carl Zeiss GmbH, Oberkochen, Germany).

\section{Morphometric analysis of fibrin structure and statistical procedures}

SEM images of the four selected plasma clots according to the $A_{340 \max }$ values (Fig. 1), and in a separate study clots from two more untreated $\mathrm{DH}$ patients and two healthy subjects (see above) were analysed to determine the diameter of the fibrin fibers using self-designed scripts running under the Image Processing Toolbox v. 7.0 of Matlab 7.10.0.499 (R2010a) (The Mathworks, Natick, MA). For the diameter measurements a grid was drawn over the image with 10-15 equally-spaced horizontal lines and all fibers crossed by them were included in the analysis. The diameters were measured manually by placing the pointer of the Distance tool over 
This is a preprint version of the paper published in J Dermatol Sci. 2016 Oct;84(1):17-23. doi: 10.1016/j.jdermsci.2016.07.005.

(C) 2016 Elsevier. This manuscript version is made available under the CC-BY-NC-ND 4.0 license

the endpoints of transverse cross-sections of 300 fibers from each image (always perpendicularly to the longitudinal axis of the fibers) and 3 images from each plasma sample were evaluated. The distribution of the measured fiber diameter data was analysed using an algorithm described previously to fit theoretical distributions to several empirical data sets [20]. The best fitted distributions for different samples were compared using Kuiper test and Monte Carlo simulation procedures. When a statistically significant difference between two distributions was established, the numerical characteristics of the central tendency and variance were considered to be statistically significant. The statistical evaluation of the lysisassay parameters (lysis time, $\mathrm{A}_{340 \mathrm{max}}$ ) was performed with Kolmogorov-Smirnov test (Statistical Toolbox 7.3 of Matlab). A p-value of less than 0.05 was considered statistically significant.

\section{RESULTS}

\section{Turbidimetric clot-lysis assay and the in vitro effect of dapsone}

The fibrinolytic potential of clots formed from fresh blood plasma (fibrinogen rich samples) and from modified fresh serum (fibrinogen-free samples supplemented with normal human fibrinogen) was evaluated in $23 \mathrm{DH}$ patients $(7 / 23$ untreated, $5 / 23$ treated with dapsone $\underline{(3 / 5 \text { also under intermittent GFD) }}, 11 / 23$ on continuous GFD) and in 12 healthy subjects by a turbidimetric lysis assay (Fig. 1). The plasma clot lysis time was significantly prolonged in the groups of untreated $(n=7)$ as well as total $\mathrm{DH}$ patients $(n=23)$ and their $A_{340 \max }$ values were significantly higher 
This is a preprint version of the paper published in J Dermatol Sci. 2016 Oct;84(1):17-23. doi: 10.1016/j.jdermsci.2016.07.005.

(C) 2016 Elsevier. This manuscript version is made available under the CC-BY-NC-ND 4.0 license

compared to healthy subjects (Fig. 2). When lysis was evaluated in clots from sera of the same patients, supplemented with exogenous fibrinogen, no significant differences were detected neither in turbidity $\left(A_{340 \max }\right)$, nor in lysis time.

Dapsone treatment in $\mathrm{DH}$ resulted in statistically significant differences in the plasma clot lysis time and $A_{340 \max }$ compared to the untreated patients, because the dapsone therapy shifted the parameters of the fibrinolytic profile towards the values of healthy subjects (Fig. 2A, 2C). A moderate (by 5-10 \%), but statistically significant decrease in both $\mathrm{A}_{340 \max }$ and lysis time was detected when dapsone at 5 $\mu \mathrm{g} / \mathrm{ml}$ was applied directly to plasma samples of 2 untreated $\mathrm{DH}$ patients for $30 \mathrm{~min}$ prior the clotting in the fibrinolytic assay (Table 2). It is noteworthy that GFD improved the fibrinolytic parameters of $\mathrm{DH}$ patients, but statistical differences persisted in both lysis time and $A_{340 \max }$ compared to healthy subjects (Fig. 2). The differences in the lysis of plasma clots from $\mathrm{DH}$ patients with and without dapsone therapy disappeared in serum studies when exogenous fibrinogen was added to serum samples (Fig. 2B, 2D).

In another set of control experiments plasma clots from pemphigus vulgaris patients $(n=5)$ showed no significant difference to plasma clots from healthy subjects $(n=7)$, neither in $A_{340 \max }$ value $(0.4603 \pm 0.09$ vs. $0.5688 \pm 0.0658)$, nor in lysis time (103.1 $\pm 15.64 \mathrm{~min}$ vs. $87.9 \pm 22.5 \mathrm{~min})$, and these values were also normal in their fibrinogen-supplemented serum clots $\left(A_{340 \max }\right.$ value $0.2551 \pm 0.024$ vs. $0.253 \pm 0.008$, lysis time $56.2 \pm 15.7 \mathrm{~min}$ vs. $59.2 \pm 0.008 \mathrm{~min}$ ) (Table 1$)$. 
This is a preprint version of the paper published in J Dermatol Sci. 2016 Oct;84(1):17-23. doi: 10.1016/j.jdermsci.2016.07.005.

(C) 2016 Elsevier. This manuscript version is made available under the CC-BY-NC-ND 4.0 license

Scanning electron microscope (SEM) imaging of plasma clots

The altered $A_{340 m a x}$ values observed in plasma clots from $\mathrm{DH}$ patients could be attributed either to variations in the fibrinogen concentration or to a modified fibrin structure. Because the fibrinogen levels of the examined plasma samples were within the normal range $(1.5-4.5 \mathrm{~g} / \mathrm{l})$, we performed direct evaluation of the fibrin structure with SEM. The fibrin network from the untreated, TG2-TG3 AB positive P1 patient showed more convoluted and thicker fibers than the clot from the healthy subject. The fibrin in plasma clots of the TG2-TG3 AB negative, dapsone treated P2 patient on GFD presented with thinner fiber diameters and loose larger pores than P1 or the healthy subject (Fig. 3A). This visual impression for existing differences in fibrin structure was further substantiated by quantitative analysis of the fiber diameter in plasma clots (Fig. 3B): The median fiber diameter in the plasma clots of the untreated $\mathrm{P} 1(137.9 \mathrm{~nm})$ was larger, as compared to the fibrin of a healthy subject (median $114.2 \mathrm{~nm}, \mathrm{p}<0.001$ ). The fibrin fibers in plasma clots from dapsone-treated patients, either under GFD (P2), or without diet (P3) were either thinner (P2) or identical in size compared to the control (Fig. 3B). In a separate study SEM evaluation of fibrin from further 2 untreated $\mathrm{DH}$ patients and 2 healthy subjects confirmed the trend of fiber thickening in $\mathrm{DH}$ (median of 113.0 and $115.6 \mathrm{~nm}$ versus 74.5 and $113.0 \mathrm{~nm}$ ). Direct application of dapsone at $5 \mu \mathrm{g} / \mathrm{ml}$ for 30 min prior clotting resulted in a significant reduction in fiber diameter in both $\mathrm{DH}$ patients and healthy subjects (to median values in the range $58.0-78.8 \mathrm{~nm}$ ). 
This is a preprint version of the paper published in J Dermatol Sci. 2016 Oct;84(1):17-23. doi: 10.1016/j.jdermsci.2016.07.005.

(C) 2016 Elsevier. This manuscript version is made available under the CC-BY-NC-ND 4.0 license

\section{DISCUSSION}

Based on the recent findings of high prevalence of cryofibrinogen in $\mathrm{DH}$ patients [9], we hypothesized a pathogenic fibrinogen/fibrin turnover in the disease. The evaluation of fibrinolysis in $\mathrm{DH}$ is justified also by the observed extravascular deposition of fibrin and fibrinogen in the papillary dermis of $\mathrm{DH}$ skin confirmed by several laboratories. These fibrin deposits are characteristic for the disease and appeared at an early stage of blister formation [[6], [7], [8]]. DH skin lesions had been initiated in vivo by autologous serum injection, but this reaction did not develop in response to plasma treated with heparin or an antifibrinolytic agent $(\varepsilon-$ aminocaproic acid) [21]. Some reports evidence the efficiency of heparin in the treatment of severe $\mathrm{DH}$ patients, who did not tolerate sulfones [[22], [23], [24]], but the exact mechanism behind this therapeutic effect has not been fully explored.

Our present study addressed the formation of fibrin, its structure and susceptibility to lysis in DH patients (untreated or treated with dapsone or GFD). The turbiditybased fibrinolytic assay used by us provides information on all of these aspects of fibrin turnover including all essential endogenous components of the system (fibrinogen with associated plasma proteins, protease inhibitors, plasminogen). Only the triggers of clotting (thrombin) and lysis (tPA) were exogenously added. Thus, the parameters gained from this assay can be considered as characteristics of the global fibrinolytic potential of plasma. The median lysis time of plasma clots from untreated $\mathrm{DH}$ patients was more than 3-fold longer in this assay compared to 
This is a preprint version of the paper published in J Dermatol Sci. 2016 Oct;84(1):17-23. doi: 10.1016/j.jdermsci.2016.07.005.

(C) 2016 Elsevier. This manuscript version is made available under the CC-BY-NC-ND 4.0 license

healthy subjects, clearly demonstrating an impaired fibrinolytic potential. The second parameter determined in the turbidimetric assay (the maximal turbidity, $\left.A_{340 \max }\right)$ is related to fibrin structure [[17], [18]], and the almost 2-fold increase of its median values in plasma clots from untreated patients indicated morphological alterations that were identified as thicker fibers with SEM evaluation. On their own such changes in fibrin structure can form the basis for increased fibrinolytic resistance of the clots as we have recently described for other modifiers of fibrin assembly (DNA and histones released by neutrophils) which also cause thickening of fibers and suppressed tPA-induced lysis [Longstaff 2013, Varjú 2015]. The specificity of changes in the fibrin structure and lysis properties for $\mathrm{DH}$ pathology was tested in comparison with measurements performed in plasma clots of pemphigus vulgaris patients, which did not show such abnormalities. This finding does not rule out the possibility for similar fibrinolytic alterations in other blistering skin diseases.

When a plasma clot is formed, a broad range of proteins associated with fibrinogen is entrapped in its structure [25]. The prevalent cryofibrinogenemia in $\mathrm{DH}$ [9] raises the possibility that the altered structural and lytic profile of fibrin in $\mathrm{DH}$ is due to a factor associated with circulating fibrinogen. This hypothesis was confirmed by our work with serum samples, in which the fibrinogen (and associated proteins) was removed and subsequently substituted with purified human fibrinogen. Such serum clots from $\mathrm{DH}$ patients did not differ in their fibrinolytic properties from clots of 
This is a preprint version of the paper published in J Dermatol Sci. 2016 Oct;84(1):17-23. doi: 10.1016/j.jdermsci.2016.07.005.

(C) 2016 Elsevier. This manuscript version is made available under the CC-BY-NC-ND 4.0 license

healthy subjects.

Thus, the impaired fibrinolytic potential and the modified fibrin structure were associated and could contribute to $\mathrm{DH}$ skin lesion initiation, supporting earlier data that suggested the role of haemostatic imbalance in cutaneous symptoms and highlighted the therapeutic effect of anticoagulation [[20], [21], [22], [24]]. An established therapeutic modality in $\mathrm{DH}$ is dapsone administration. The favourable effect of dapsone on fibrinolysis and fibrin structure in $\mathrm{DH}$ evidenced by the present study represents a novel aspect of its therapeutic action complementary to previously hypothesized mechanisms [26]. In addition, it furthers our understanding of dapsone effectiveness in cryofibrinogenemia-associated diseases [10] (Kárpáti et al., 1997) and different vasculitis forms [27].

Alterations of fibrinolysis are known to exist in other autoimmune blistering skin diseases, e.g. inhibited fibrinolysis was found in active bullous pemphigoid and it improved after systemic corticosteroid treatment [28]. In the blood of $\mathrm{DH}$ patients a significantly lower urokinase plasminogen activator concentration, plasminogen level, $\alpha_{2}$-antiplasmin activity and higher plasminogen activator inhibitor-1 and plasmin- $\alpha_{2}$-antiplasmin complex concentration were demonstrated [29]. Some of these changes in the systemic levels of fibrinolytic factors in $\mathrm{DH}$ (elevated plasminogen activator inhibitor-1, lower plasminogen) are probably related to the underlying inflammatory processes and could also contribute to the retarded 
This is a preprint version of the paper published in J Dermatol Sci. 2016 Oct;84(1):17-23. doi: 10.1016/j.jdermsci.2016.07.005.

(C) 2016 Elsevier. This manuscript version is made available under the CC-BY-NC-ND 4.0 license

fibrinolysis revealed by the present study (in addition to the lytic consequences of altered fibrin structure).

In summary, we observed a reduced fibrinolytic potential and modified fibrin structure of plasma clots in untreated $\mathrm{DH}$, whereas the reduced fibrinolytic potential and the structural abnormalities of fibrin were reversed under dapsone treatment. The association of active symptomatic skin disease with fibrinolytic abnormalities in plasma and the parallel normalization of skin symptoms and clot properties under efficient therapy suggest that fibrin(ogen) turnover is involved in the pathomechanism of $\mathrm{DH}$. Future elucidation of the mechanistic contribution of fibrin and cryofibrinogen to the progress of the local skin lesions could delineate new avenues for therapeutic intervention in $\mathrm{DH}$.

\section{ACKNOWLEDGMENTS}

The authors thank Györgyi Oravecz, Mercédesz Mazán, Dóra Pintér and Krisztián Bálint for their excellent technical assistance. We appreciate the contribution of the patients for their participations. This work was supported by the Hungarian Scientific Research Fund [OTKA 112612 and OTKA NN 114460]. 
This is a preprint version of the paper published in J Dermatol Sci. 2016 Oct;84(1):17-23. doi: 10.1016/j.jdermsci.2016.07.005.

(C) 2016 Elsevier. This manuscript version is made available under the CC-BY-NC-ND 4.0 license

\section{REFERENCES}

[1] S. Karpati, E. Torok, I. Kosnai, Discrete palmar and plantar symptoms in children with dermatitis herpetiformis Duhring. Cutis. 37 (1986) 184-187. 
This is a preprint version of the paper published in J Dermatol Sci. 2016 Oct;84(1):17-23. doi: 10.1016/j.jdermsci.2016.07.005.

(C) 2016 Elsevier. This manuscript version is made available under the CC-BY-NC-ND 4.0 license

[2] S. Kárpáti- An exception within the group of autoimmune blistering diseases: dermatitis herpetiformis, the gluten-sensitive dermopathy, Immunol. Allergy. Clin. North. Am. 32 (2012) 255-262.

[3] M. Sárdy, S. Kárpáti, B. Merkl, M. Paulsson, N. Smyth, Epidermal transglutaminase (TGase 3 ) is the autoantigen of dermatitis herpetiformis, J. Exp. Med. 195 (2002) 747-757.

[4] K.K. Mustakallio, K. Blomqvist, O.P. Salo, Papillary fibrin in dermatitis herpetiformis, Arch. Belg. Dermatol. Syphiligr. 26 (1970) 441-447.

[5] O.P. Salo, K. Laiho, K. Blomqvist, K.K. Mustakallio, Papillary deposition of fibrin in iodide reactions in dermatitis herpetiformis, Ann. Clin. Res. 2 (1970) 19-21.

[6] K. Jakubowicz, J. Dabrowski, W. Maciejewski, Deposition of fibrin-like material in early lesions of dermatitis herpetiformis, Br. J. Dermatol. 105 (1981) 167-177.

[7] S. Reitamo, T. Reunala, Y.T. Konttinen, O. Saksela, O.P. Salo, Inflammatory cells, IgA, C3, fibrin and fibronectin in skin lesions in dermatitis herpetiformis, $\mathrm{Br}$. J. Dermatol. 105 (1981) 167-177.

[8] T.B. Taylor, L.A. Schmidt, L.J. Meyer, J.J. Zone, Transglutaminase 3 Present in the IgA Aggregates in Dermatitis Herpetiformis Skin Is Enzymatically Active and Binds Soluble Fibrinogen, J. Invest. Dermatol. 135 (2015) 623-625.

[9] P. Bognár, A. Görög, S. Kárpáti, High prevalence of cryofibrinogenemia in dermatitis herpetiformis, J. Eur. Acad. Dermatol. Venereol. 2014 [Epub ahead of print] (doi: 10.1111/jdv.12913) 
This is a preprint version of the paper published in J Dermatol Sci. 2016 Oct;84(1):17-23. doi: 10.1016/j.jdermsci.2016.07.005.

(C) 2016 Elsevier. This manuscript version is made available under the CC-BY-NC-ND 4.0 license

[10] S. Karpati, M. Sardy, M. Marschalko, A. Horvath. New clinical approach in treatment of cryofibrinogenemia - diamino-diphenyl-sulfone seems to decrease the amount of cold precipitated serum-proteins-in vitro, J. Invest. Dermatol. 109 (1997) 463 (Abstr.)

[11] Z. Bagoly, Z. Koncz, J. Harsfalvi, L. Muszbek, Factor XIII, clot structure, thrombosis, Thromb. Res. 129 (2012) 382-387.

[12] Z. Bagoly, E. Katona, L. Muszbek, Factor XIII and inflammatory cells, Thromb. Res. 129 (2012) Suppl 2: S77-81.

[13] K. Kolev, C. Longstaff, R. Machovich, Fibrinolysis at the fluid-solid interface of thrombi, Curr. Med. Chem. Cardiovasc. Hematol. Agents. 3 (2005) 341-355.

[14] C. Longstaff, K. Kolev, Basic mechanisms and regulation of fibrinolysis, J. Thromb. Haemost. 13 (2015) S98-S105.

[15] K. Kolev, J. Gombás, B. Váradi, J. Skopál, K. Mede, E. Pitlik, Z. Nagy, et al., Immunglobulin $G$ from patients with antiphospholipid syndrome impairs the fibrin dissolution with plasmin, Thromb. Haemost. 87 (2002) 502-508.

[16] C. Longstaff, C. Thelwell, S. Williams, M.M. Silva, L. Szabó, K. Kolev, The interplay between tissue plasminogen activator domains and fibrin structures in the regulation of fibrinolysis: kinetic and microscopic studies, Blood 117 (2011) 661-668.

[17] B. Blomback, K. Carlsson, K. Fatah, B. Hessel, L. Procyk, Fibrin in human plasma: gel architecture governed by rate and nature of fibrinogen activation, Thromb. Res. 75 (1994) 521-538. 
This is a preprint version of the paper published in J Dermatol Sci. 2016 Oct;84(1):17-23. doi: 10.1016/j.jdermsci.2016.07.005.

(C) 2016 Elsevier. This manuscript version is made available under the CC-BY-NC-ND 4.0 license

[18] M.E. Carr, R.M. Dent, S.L. Carr, Abnormal fibrin structure and inhibition of fibrinolysis in patients with multiple myeloma, J. Lab. Clin. Med. 128 (1996) 83-88.

[19] J. Zuidema, E.S. Hilbers-Modderman, F.W. Merkus, Clinical pharmacokinetics of dapsone, Clin. Pharmacokinet. 11 (1986) 299-315.

[20] N.D. Nikolova, D. Toneva-Zheynova, K. Kolev, K. Tenekedjiev, Monte Carlo statistical tests for identity of theoretical and empirical distributions of experimental data. In: Chan WK, ed. Theory and Applications of Monte Carlo Simulations. Rijeka, Croatia: InTech: (2013) 1-26. DOI: 10.5772/53049

[21] N.H. Cox, P.S. Friedmann, Induction of lesions of dermatitis herpetiformis by autologous serum, Br. J. Dermatol. 124 (1991) 69-73.

[22] J. Alexander, The treatment of dermatitis herpetiformis with heparin, $\mathrm{Br}$. J. Dermatol. 75 (1963) 289-293.

[23] C.C. Tan, J.E. Sale, C. Brammer, R.P. Irons, J.G. Freeman, A rare case of dermatitis herpetiformis requiring parenteral heparin for long-term control, Dermatology 192 (1996) 185-186.

[24] S.A. Shah, A.D. Ormerod, Dermatitis herpetiformis effectively treated with heparin, tetracycline and nicotinamide, Clin. Exp. Dermatol. 25 (2000) 204-205.

[25] S. Talens, F.W. Leebeek, J.A. Demmers, D.C. Rijken, Identification of fibrin clot-bound plasma proteins, PLoS One 7 (2012) e41966.

[26] G. Wozel, C. Blasum, Dapson in dermatology and beyond, Arch. Dermatol. Res. 306 (2014) 103-124. 
This is a preprint version of the paper published in J Dermatol Sci. 2016 Oct;84(1):17-23. doi: 10.1016/j.jdermsci.2016.07.005.

(C) 2016 Elsevier. This manuscript version is made available under the CC-BY-NC-ND 4.0 license

[27] M.R. Goeser, V. Laniosz, D.A. Wetter, A practical approach to the diagnosis, evaluation and management of cutaneous small-vessel vasculitis, Am. J. Clin. Dermatol. 15 (2014) 299-306.

[28] A.V. Marzano, A. Tedeschi, I. Polloni, C. Crosti, M. Cugno, Prothrombotic state and impaired fibrinolysis in bullous pemphigoid, the most frequent autoimmune blistering disease, Clin. Exp. Immunol. 171 (2013) 76-81.

[29] A. Wankiewicz, I. Iwan-Zietek, M. Kotschy, Z. Gwieździński, Selected parameters of fibrinolysis system in patients with dermatitis herpetiformis, Med. Sci. Monit. 8 (2002) 189-192.

C. Longstaff, I. Varjú, P. Sótonyi, L. Szabó, M. Krumrey, A. Hoell, A. Bóta, Z. Varga, E. Komorowicz, K. Kolev, Mechanical stability and fibrinolytic resistance of clots containing fibrin, DNA, and histones, J. Biol. Chem. 288 (2013) 6946-6956

I. Varjú, C. Longstaff, L. Szabó, Á.Z. Farkas, V.J. Varga-Szabó, A. TankaSalamon, R. Machovich, K. Kolev, DNA, histones and neutrophil extracellular traps exert anti-fibrinolytic effects in a plasma environment, Thromb. Haemost. 113 (2015) 1289-1298 
This is a preprint version of the paper published in J Dermatol Sci. 2016 Oct;84(1):17-23. doi: 10.1016/j.jdermsci.2016.07.005.

(C) 2016 Elsevier. This manuscript version is made available under the CC-BY-NC-ND 4.0 license

\section{LEGENDS}

Fig. 1. Formation and dissolution of plasma $(A)$ and serum (B) clots monitored by turbidity. Tissue-type plasminogen activator was added to anticoagulated plasma or to serum supplemented with fibrinogen, and clotting was initiated with thrombin and $\mathrm{Ca}^{2+}$. The absorbance was continuously monitored at $340 \mathrm{~nm}\left(\mathrm{~A}_{340}\right)$ as an indicator of clot formation (ascending phase up to $A_{340 \max }$ ) and lysis (descending phase). The lysis time - defined as the time needed to reduce the turbidity of the clot to half-maximal value - was used as a quantitative parameter of fibrinolytic activity, whereas the $A_{340 \max }$ as an indicator of fibrin structure. Each curve was generated as the mean value of eight parallel measurements. Data for untreated DH patients are shown with continuous lines, whereas dashed lines are used for DH patients under treatment. P1, P2 and P3 indicate the patients 1, 2 and 3 (see Table 1) selected for evaluation of their plasma clot ultrastructure.

Fig. 2. Quantitative assessment of the fibrinolytic potential of plasma (2A, $2 \mathrm{C})$ and serum $(2 B, 2 D)$ clots. Lysis time and $A_{340 \max }$ were derived from the experimental setup shown in Fig. 1. Each symbol represents the mean value of eight 
This is a preprint version of the paper published in J Dermatol Sci. 2016 Oct;84(1):17-23. doi: 10.1016/j.jdermsci.2016.07.005.

(C) 2016 Elsevier. This manuscript version is made available under the CC-BY-NC-ND 4.0 license

independent experiments from a single sample ( $p$ values refer to KolmogorovSmirnov test for data distribution in the total, dapsone and gluten-free diet (GFD) treated and untreated groups of $\mathrm{DH}$ patients compared to healthy subjects as well as dapsone and GFD treated patients to untreated patients).

Fig. 3. Ultrastructure of clot fibrin network by scanning electron microscopy (SEM). (A) Plasma clots were examined after 30 min clotting (scale bar $=1 \mu \mathrm{m})$. Patient $(P)$ samples were selected based on their fibrinolytic profiles shown in Figure 1: P1, a TG2-TG3 antibody positive, untreated patient; P2, a TG2-TG3 antibody negative, dapsone treated patient, under gluten-free diet; P3, a TG2 antibody negative-TG3 antibody positive, only dapsone treated patient. (B) Diameter of 300 fibers was measured and their empirical (black histograms) as well as best-fitted theoretical (gray curves) probability density functions (PDF) were determined. Median values and interquartile range are shown for theoretical distributions of diameter values (see Materials and Methods).

\section{TABLES AND FIGURES}


This is a preprint version of the paper published in J Dermatol Sci. 2016 Oct;84(1):17-23. doi: 10.1016/j.jdermsci.2016.07.005.

(C) 2016 Elsevier. This manuscript version is made available under the CC-BY-NC-ND 4.0 license

Table 1. Summary of clinical and laboratory data of $\mathrm{DH}$ patients $(n=23)$ by the turbidimetric clot lysis-assay and as a separate set, data of pemphigus vulgaris patients $(n=5)$.

\begin{tabular}{|c|c|c|c|c|c|c|c|c|c|c|c|}
\hline Patients & $\begin{array}{l}\text { Age/ } \\
\text { Sex }\end{array}$ & $\begin{array}{c}\text { Duration } \\
\text { of } \mathrm{DH} / \\
\text { pemphigu } \\
\text { s vulgaris }\end{array}$ & $\begin{array}{c}\text { Skin } \\
\text { sympto } \\
m^{1}\end{array}$ & GFD & $\begin{array}{c}\text { Dapson } \\
\mathrm{e}\end{array}$ & EMA & $\begin{array}{c}\text { anti-TG2 } \\
\text { IgA ELISA } \\
(\mathrm{AU} / \mathrm{ml})^{2}\end{array}$ & $\begin{array}{c}\text { anti-TG3 } \\
\lg \mathrm{A} \\
\text { ELISA } \\
(\mathrm{AU} / \mathrm{ml})^{3}\end{array}$ & $\begin{array}{l}\text { Cryo- } \\
\text { protein }\end{array}$ & $\begin{array}{c}\text { Lysis } \\
\text { time in } \\
\text { plasma/ } \\
\text { serum } \\
(\min )^{4}\end{array}$ & $\begin{array}{c}\mathrm{A}_{340} \\
\text { in } \\
\text { plasma/ } \\
\text { serum }{ }^{4}\end{array}$ \\
\hline $1=P 1$ & $31 / F$ & $6 y$ & Yes & No & No & Pos & $>100$ & 235 & Neg & $\begin{array}{l}39.5 / \\
58.6\end{array}$ & $\begin{array}{l}0.634 / \\
0.191\end{array}$ \\
\hline $2=P 2$ & $26 / \mathrm{F}$ & $8 y$ & Yes & Yes & Yes & $\mathrm{Neg}$ & $<10$ & 20 & Neg & $\begin{array}{l}20.6 / \\
73.7\end{array}$ & $\begin{array}{l}0.202 / \\
0.316 \\
\end{array}$ \\
\hline $3=P 3$ & $44 / M$ & $33 y$ & No & No & Yes & Pos & $<10$ & 33 & $\mathrm{CF}++$ & $\begin{array}{l}35.2 / \\
100.5 \\
\end{array}$ & $\begin{array}{l}0.314 / \\
0.262 \\
\end{array}$ \\
\hline 4 & $36 / \mathrm{M}$ & $1 y$ & Yes & No & No & $\mathrm{Neg}$ & $<10$ & 20 & Neg & $\begin{array}{c}121.1 / \\
88.2 \\
\end{array}$ & $\begin{array}{l}0.345 / \\
0.239 \\
\end{array}$ \\
\hline 5 & $30 / \mathrm{F}$ & $25 y$ & No & Yes & No & $\mathrm{Neg}$ & $<10$ & 15 & Neg & $\begin{array}{l}93.3 / \\
69.5 \\
\end{array}$ & $\begin{array}{l}0.409 / \\
0.268\end{array}$ \\
\hline 6 & $29 / M$ & $23 y$ & No & Yes & No & $\mathrm{Neg}$ & $<10$ & 10 & $\mathrm{CF}+$ & $\begin{array}{l}31.0 / \\
82.7\end{array}$ & $\begin{array}{l}0.495 / \\
0.251\end{array}$ \\
\hline 7 & $27 / F$ & $23 y$ & No & Yes & No & $\mathrm{Neg}$ & $<10$ & 5 & $\mathrm{CF}+$ & $\begin{array}{l}35.2 / \\
41.4 \\
\end{array}$ & $\begin{array}{l}0.561 / \\
0.261 \\
\end{array}$ \\
\hline 8 & $21 / \mathrm{M}$ & $15 y$ & No & Yes & No & $\mathrm{Neg}$ & $<10$ & 9 & Neg & $\begin{array}{l}31.0 / \\
45.4\end{array}$ & $\begin{array}{l}0.387 / \\
0.251\end{array}$ \\
\hline 9 & $60 / M$ & $10 y$ & No & Yes & No & $\mathrm{Neg}$ & $<10$ & 20 & $\mathrm{CF}+$ & $\begin{array}{l}38.6 / \\
92.1\end{array}$ & $\begin{array}{l}0.318 / \\
0.265\end{array}$ \\
\hline 10 & $29 / M$ & $6 y$ & No & Yes & No & $\mathrm{Neg}$ & $<10$ & 2 & Neg & $\begin{array}{l}50.1 / \\
64.3 \\
\end{array}$ & $\begin{array}{l}0.361 / \\
0.273 \\
\end{array}$ \\
\hline 11 & $27 / M$ & $24 y$ & No & Yes & No & $\mathrm{Neg}$ & $<10$ & 8 & Neg & $\begin{array}{l}56.6 / \\
82.2\end{array}$ & $\begin{array}{l}0.387 / \\
0.241 \\
\end{array}$ \\
\hline 12 & $26 / \mathrm{M}$ & $5 y$ & No & Yes & No & $\mathrm{Neg}$ & $<10$ & 1 & Neg & $\begin{array}{l}46.0 / \\
66.3 \\
\end{array}$ & $\begin{array}{l}0.350 / \\
0.172 \\
\end{array}$ \\
\hline 13 & $61 / \mathrm{M}$ & $1 y$ & No & Yes & Yes & $\mathrm{Neg}$ & $<10$ & 35 & Neg & $\begin{array}{l}29.5 / \\
78.7 \\
\end{array}$ & $\begin{array}{l}0.301 / \\
0.247 \\
\end{array}$ \\
\hline 14 & $64 / \mathrm{F}$ & $8 y$ & Yes & No & Yes & $\mathrm{Neg}$ & $<10$ & 15 & Neg & $\begin{array}{l}30.8 / \\
53.4 \\
\end{array}$ & $\begin{array}{l}0.452 / \\
0.272 \\
\end{array}$ \\
\hline 15 & $23 / M$ & $17 y$ & No & Yes & No & $\mathrm{Neg}$ & $<10$ & 8 & Neg & $\begin{array}{l}31.4 / \\
152.9 \\
\end{array}$ & $\begin{array}{l}0.312 / \\
0.224 \\
\end{array}$ \\
\hline 16 & $43 / \mathrm{M}$ & $23 y$ & Yes & Yes & Yes & $\mathrm{Neg}$ & $<10$ & 15 & Neg & $\begin{array}{l}38.4 / \\
97.1 \\
\end{array}$ & $\begin{array}{l}0.352 / \\
0.282 \\
\end{array}$ \\
\hline 17 & $45 / M$ & $1 y$ & Yes & Yes & No & $\mathrm{Neg}$ & $<10$ & 20 & $\mathrm{CF}+$ & $\begin{array}{l}31.8 / \\
76.5 \\
\end{array}$ & $\begin{array}{l}0.302 / \\
0.241 \\
\end{array}$ \\
\hline 18 & $44 / \mathrm{M}$ & $37 y$ & Yes & No & No & Pos & $>100$ & 80 & $\begin{array}{c}\mathrm{CF}++ \\
\mathrm{CG}+\end{array}$ & $\begin{array}{l}55.8 / \\
51.3\end{array}$ & $\begin{array}{l}0.4371 \\
0.220\end{array}$ \\
\hline 19 & $49 / M$ & $1 y$ & Yes & No & No & $\mathrm{Neg}$ & $<10$ & 16 & $\mathrm{Neg}$ & $\begin{array}{c}103.5 / \\
69.6\end{array}$ & $\begin{array}{l}0.418 / \\
0.219\end{array}$ \\
\hline 20 & $40 / \mathrm{F}$ & $31 y$ & No & Yes & No & $\mathrm{Neg}$ & $<10$ & 5 & Neg & $\begin{array}{l}42.4 / \\
65.5 \\
\end{array}$ & $\begin{array}{l}0.382 / \\
0.278\end{array}$ \\
\hline 21 & $44 / M$ & $5 y$ & Yes & No & No & Pos & $>100$ & 103 & $\mathrm{CF}+$ & $\begin{array}{l}25.4 / \\
66.8 \\
\end{array}$ & $\begin{array}{l}0.275 / \\
0.208 \\
\end{array}$ \\
\hline 22 & $74 / M$ & $1 y$ & Yes & No & No & Pos & $>100$ & $>200$ & $\mathrm{Neg}$ & $\begin{array}{l}98.8 / \\
33.4 \\
\end{array}$ & $\begin{array}{l}0.542 / \\
0.272\end{array}$ \\
\hline 23 & $68 / M$ & $6 \mathrm{~m}$ & Yes & No & No & $\mathrm{Neg}$ & 22 & 77 & Neg & \begin{tabular}{|l}
$79.3 /$ \\
31.6 \\
\end{tabular} & $\begin{array}{l}0.424 / \\
0.256\end{array}$ \\
\hline PV1 & $66 / F$ & $4 m$ & Yes & No & No & $\mathrm{Neg}$ & $<10$ & 2 & $\mathrm{NA}$ & $\begin{array}{c}111.3 / \\
52.8\end{array}$ & $\begin{array}{l}0.455 / \\
0.297\end{array}$ \\
\hline PV2 & $74 / F$ & $1 \mathrm{~m}$ & Yes & No & No & $\mathrm{Neg}$ & $<10$ & 5 & $\overline{N A}$ & $\begin{array}{c}116.2 / \\
56.2\end{array}$ & $\begin{array}{l}0.537 / \\
0.240\end{array}$ \\
\hline PV3 & $41 / \mathrm{F}$ & $2 m$ & Yes & No & No & $\mathrm{Neg}$ & $<10$ & 1 & NA & $\begin{array}{l}78 / 3 \\
32.6 \\
\end{array}$ & $\begin{array}{l}0.343 / \\
0.249 \\
\end{array}$ \\
\hline
\end{tabular}


This is a preprint version of the paper published in J Dermatol Sci. 2016 Oct;84(1):17-23. doi: 10.1016/j.jdermsci.2016.07.005.

(C) 2016 Elsevier. This manuscript version is made available under the CC-BY-NC-ND 4.0 license

\begin{tabular}{|c|c|c|c|c|c|c|c|c|c|c|c|}
\hline PV4 & $49 / \mathrm{F}$ & $2 \mathrm{~m}$ & Yes & No & No & Neg & $<10$ & 4 & NA & $\begin{array}{c}112.5 / \\
63.9\end{array}$ & $\begin{array}{c}0.319 / \\
0.251\end{array}$ \\
\hline PV5 & $60 / \mathrm{F}$ & $2 \mathrm{~m}$ & Yes & No & No & Neg & $<10$ & 1 & NA & $\begin{array}{c}97.3 / \\
75.2\end{array}$ & $\begin{array}{c}0.460 / \\
0.236\end{array}$ \\
\hline
\end{tabular}

Abbreviations: $A_{340}$, light absorbance value at $340 \mathrm{~nm}$; CF, cryofibrinogen; CG, cryoglobulin; DH, dermatitis herpetiformis; ELISA, enzyme-linked immunosorbent assay; EMA, endomysial antibodies; F, female; GFD, gluten-free diet; IgA, immunoglobulin $A ; y$, year; m, month; $M$, male; NA, not available; Neg, negative; Pos, positive; TG, transglutaminase

1 At the time of blood sample collection.

2 positive: $>10 \mathrm{AU} / \mathrm{ml}$, negative: $\leq 10 \mathrm{AU} / \mathrm{ml}$

3 positive: $>22 \mathrm{AU} / \mathrm{ml}$, negative: $\leq 22 \mathrm{AU} / \mathrm{ml}$

4 Plasma / serum samples were examined by turbidimetric clot-lysis assay. Serum samples were supplemented with purified human fibrinogen.

Table 2. Direct effect of dapsone on the fibrinolytic parameters of plasma from untreated DH patients. Dapsone at $5 \mu \mathrm{g} / \mathrm{ml}$ was applied to plasma samples of 2 untreated $\mathrm{DH}$ patients (S1, S2) for 30 min prior the clotting in the fibrinolytic assay performed as described in Fig. 1A. Maximal turbidity $\left(\mathrm{A}_{340 \mathrm{max}}\right)$ and lysis time values are presented as mean $\pm S D, n=8$. Asterisk indicates significant difference between the parameters of the dapsone-treated and the respective native plasma clots at $p<0.05$ according to Kolmogorov-Smirnov test.

\begin{tabular}{|l|c|c|c|c|}
\hline & \multicolumn{2}{|c|}{$\mathrm{A}_{340 \max }$} & \multicolumn{2}{c|}{ lysis time $(\mathrm{min})$} \\
\hline & no additive & + dapsone & no additive & + dapsone \\
\hline S1 & $0.542 \pm 0.038$ & $0.501^{*} \pm 0.018$ & $96.81 \pm 9.14$ & $85.53^{*} \pm 4.65$ \\
\hline S2 & $0.424 \pm 0.014$ & $0.384^{*} \pm 0.013$ & $79.28 \pm 3.48$ & $75.09^{\star} \pm 2.25$ \\
\hline
\end{tabular}



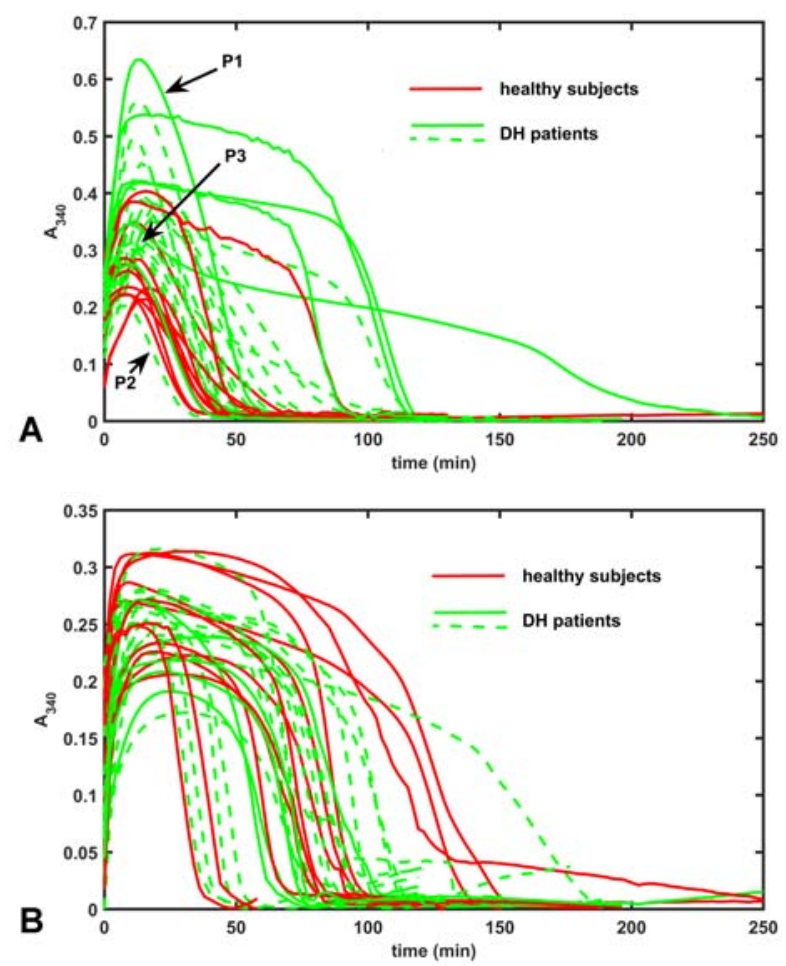

Figure 1 

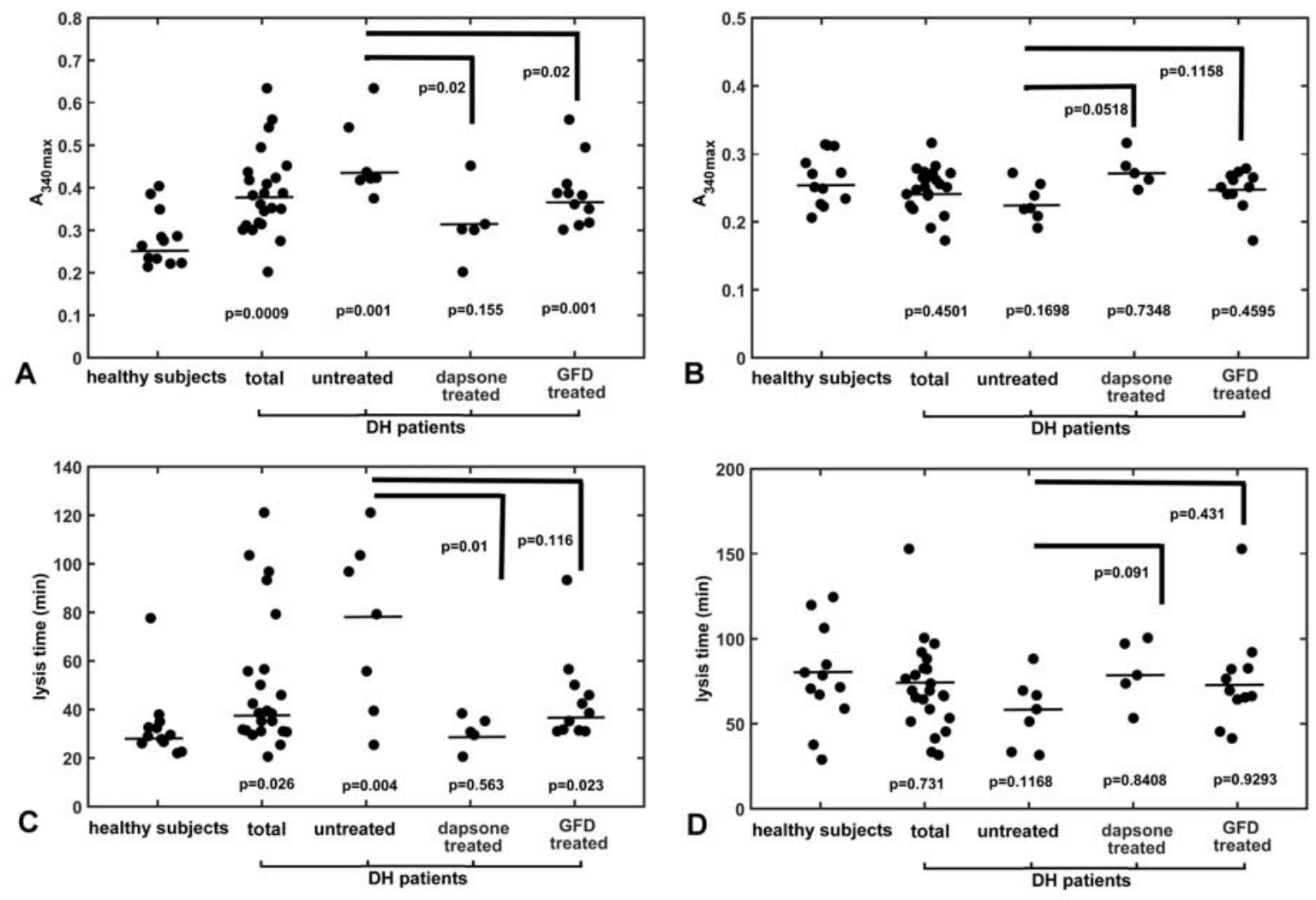

Figure 2 


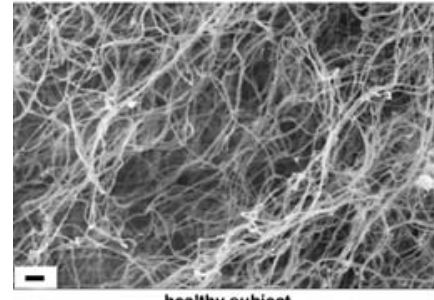

healthy subject
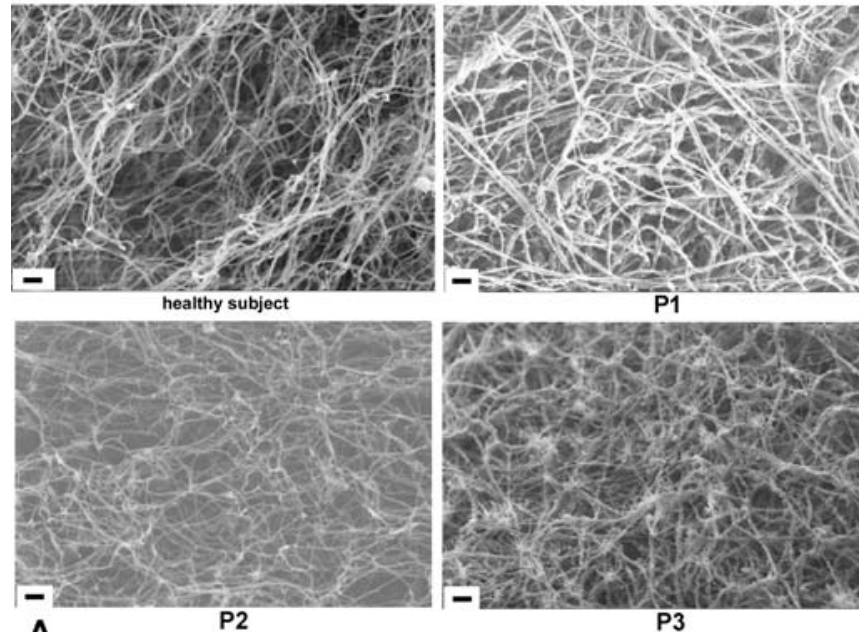

A
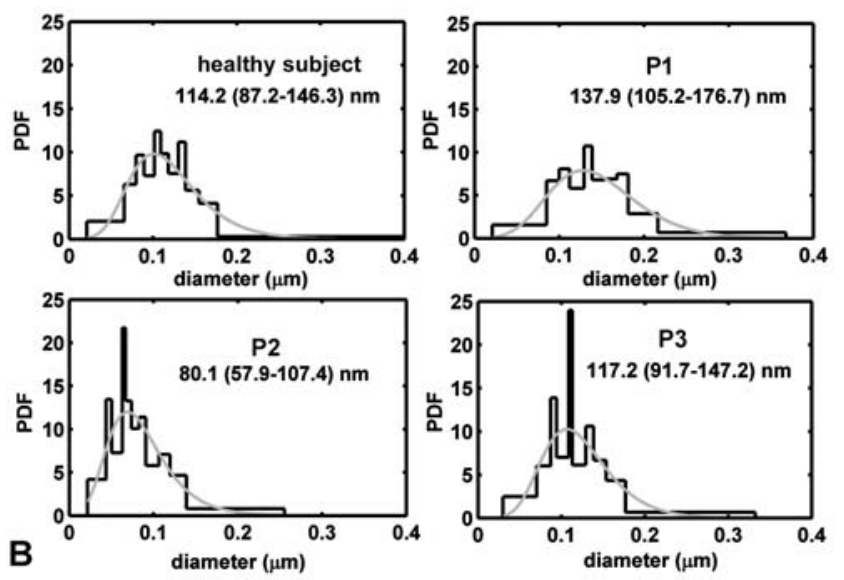

Figure 3 